\title{
JUAN DE ALEJANDRÍA, MÉDICO DEL SIGLO VII DE LA ERA CRISTIANA
}

\author{
GONZALO FERNÁNDEZ \\ Universidad de Valencia \\ Palabras clave
}

Alejandría. Filosofía. Medicina. Islam.

\begin{abstract}
This article deals with the physician John of Alexandria who lives in the Seventh Century A.D.
\end{abstract}

La tradición islámica posterior atribuye al filósofo alejandrino Juan "el Gramático" unos tratados médicos conservados en árabe y le hace coetáneo de la conquista árabe de Alejandría en 641. Dichas obras pertenecientes al arte de Esculapio son la colección de enseñanza titulada los Dieciséis libros de Galeno (obra pseudonímica que recoge el canon galénico del conocimiento de la salud) y unos escritos abreviados sobre cada uno de los referidos Dieciséis libros de Galeno, una historia de la medicina griega y un comentario al primer libro De antidotis de Galeno. Las mismas fuentes consideran a Juan "el Gramático" autor de unos Comentarios y Escolios a Aristóteles ${ }^{1}$.

Esas noticias se equivocan. Juan "el Gramático" vive aproximadamente entre 490 y la década $570-580^{2}$. Recogen, empero, la memoria de sus Comentarios a algunos escritos del Estagirita que superan al mero Organon. Ese conjunto de obras se dedica a la lógica. Comprende los Predicamenta o Categoriae, De interpretatione, Analytica priora, Analytica posteriora, Topica y De sophisticis elenchis. A partir de c.a. 543, cuando el obispo Sergio llega al obispado de Alejandría, los obispos de la ciudad sólo permiten enseñar a los maestros cristianos la lógica aristotélica y los primeros argumentos analíticos con arreglo al tratado de AlFarabi que lleva por título Sobre los inicios de la filosofia griega ${ }^{3}$, Youh-

\footnotetext{
${ }^{1}$ Vid. M. MEYERHOF, “Joannes Grammatikos (Philoponos) von Alexandrien und die arabische Medizin”, Mitteilungen des Deutschen Institut für Aegyptische Altertumskunde in Kairo, 2, 1931, págs. 20-21.

${ }^{2}$ Vid. R. SORABJI, "John Philoponus" en R. SORABJI (ed.), Philoponus and the Rejection of Aristotelian Science, Londres, 1987, pág. 1.

${ }^{3}$ Vid. IBN ABI OSAIBI'A, Oyoun al - anbâ, vol. II, El Cairo, 1882, pág. 135.
} 
anna Ibn Hailan y Mohammed Ibn Zahariyyâ ar - Râzî .

Juan "el Gramático" hace caso omiso de esta medida pese a su amistad con aquel obispo a quien dedica su De opificio mundo y De arbitrio, éste último a raíz de la buena acogida del primero por Sergio. En el seno de sus escritos filosóficos Juan "el Gramático" comenta el Fedón platónico $^{5}$ y las siguientes obras del Estagirita: Categoriae, Analytica priora, Analytica posteriora, De sophisticis elenchis, Topica, De anima, Physica, De caelo, De generatione et corruptione, Meteorologica y Metaphysica ${ }^{6}$. Juan "el Gramático" va más allá del Organon aristotélico y trasciende con mucho los límites impuestos por el obispo Sergio a la docencia cristiana alusiva al Estagirita. Ello se explica porque la escuela filosófica de Alejandría no depende de la sede episcopal. En los inicios de siglo V los obispos alejandrinos habían impulsado el traslado a la localidad de Side en Panfilia del "Didaskaleion " o escuela catequética (que sí les estaba subordinada) por sus viejas adherencias a las tesis más radicales de la "Logostheologie". La escuela filosófica de Alejandría se sostiene con las ayudas del municipio y los estipendios de los alumnos ${ }^{7}$. En esto se diferencia del conjunto de escuelas de Constantinopla, inaugurado de forma unitaria por Teodosio II en 425, que percibe sus emolumentos del Erario. Asimismo se distingue de la escuela neoplatónica de Atenas que se sufraga de la fortuna del mismo Platón aunque incrementada a lo largo del tiempo con las donaciones de los partidarios de su filosofía.

M. Meyerhof extrae estas conclusiones de su estudio en torno a los vínculos de Juan "el Gramatico" con la medicina árabe ${ }^{8}$ :

1. El Juan de Alejandría, a quien la literatura árabe atribuye los Comentarios a Aristóteles y Galeno, se identifica con Juan "el Gramático". La tesis de H. Diels con arreglo a la cual habría otro Juan de Alejandría,

\footnotetext{
${ }^{4}$ Acerca de estos dos últimos autores vid. E. RENAN, De philosophia peripatetica apud Syros, París, 1862, pág. 40, M. STEINSCHNEIDER, Al Farabi, San Petersburgo, 1869, pág. 86, n. 5 y L. LECLERCO, Histoire de la médecine arabe, vol. I, París, 1876, pág. 360.

5 En sus escritos teológicos Juan "el Gramático" defiende el conocimiento del Antiguo Testamento por Platón. Esta idea constituye un tópico de la teología alejandrina del siglo VI según A. GUDEMAN, s.V "Ioannes Philoponus, griechischer Grammatiker und christlicher Theologe" en G. WISSOWA y W. KROLL (eds.), Paulys Realencyclopädie der classischen Altertumsurissenschaft. Achtzehnter Halbband, Stuttgart, 1916, col. 1790.

${ }^{6}$ Vid. "ut supra n. 5", cols 1.772-1.781.

${ }^{7}$ Vid. L. G. WESTERINK (ed), Anonymous Prolegomena to Platonic Philosophy, Amsterdam, 1962, pág. XIV.

${ }^{8}$ Vid "ut supra n.1"
} 
autor éste último de los Escolios a Aristóteles, aún dista de haber sido probada.

2.

La localización de la vida de Juan "el Gramático", al tiempo de la conquista árabe de Egipto, es un error que aparece en los manuscritos griegos de su Comentario a la Física de Aristóteles. De aquí pasa a las versiones sirias y árabes del tratado. Probablemente se debe al bibliógrafo musulmán Ibn an-Nadin en su Fihrst, datado en 987 d.C. la leyenda del encuentro en 641 de Juan "el Gramático" con el general árabe Amr Ibn Al-'Asî.

3. El adorno de este relato y el nexo de Juan "el Gramático" con el incendio de la Biblioteca de Alejandría es un yerro del susodicho Ibn anNadin que se transmite por medio de Ibn al-Oifti, escritor que muere en 1248 a quien los cristianos llaman Furlani ${ }^{9}$

4. Los sirios poseen la totalidad de los Comentarios a Aristóteles y los escritos Teológicos de Juan "el Gramático" vertidos en su lengua y gracias a ellos son conocidos por los árabes. Juan "el Gramático" es una autoridad en la enseñanza teológica sirio-jacobita y un soporte de la teodicea arábigo-islámica (Al-Gazali) y arábigo-judía (Maimónides)

5. Los escritos sobre medicina que los árabes atribuyen a Juan "el Gramático" se clasifican en cuatro grupos:

A. Su participación en la génesis de la colección de enseñanzas médicas que se titula los Dieciséis libros de Galeno y recoge el canon galénico del conocimiento de la salud. Este testimonio corresponde al autor árabe del siglo XI Ibn Abi Usaibiá aunque en el siglo XIII el habitualmente mejor informado Ubaidallah b. Gibrail rechaza su veracidad

B. Escritos abreviados grecotardíos sobre cada uno de los precitados Dieciséis libros de Galeno. Sólo se conservan en traducciones hebreas y árabes. Ibn an-Nadin entrevé su autoría por Juan "el Gramático" que sólo aparece expresa de forma tajante por Ibn Abi Usaib'ia. Podrían atribuirse a un médico alejandrino de los siglos VI o VII d.C. (vg. Paladio, Gesio, Sergio, etc...).

C. Una historia de la medicina griega con arreglo a la noticia apor-

\footnotetext{
9 El historiador persa Asir ad-Din al-Baihaqî , quien fallece en 1175, hace nacer a Juan "el Gramático" en Persia y le considera maestro del nieto del califa omeya Mo'âuriya (661-680). Acerca de este punto vid. M. MEYERHOF, “La fin de l'École d'Álexandrie d'aprés quelques auteurs arabes”, Archeion, 15, 1933, pág. 7.
} 
tada en 903 por Ishaq b. Hunain. Ha llegado a nuestros días en estado fragmentario. M. Meyerhof la califica de chapuza fantástica llena de cuentos mágicos e indigna del ingenio de Juan "el Gramático".

D. Un comentario al primer libro del De antidotis de Galeno al que el referido tratadista considera un exponente místico-mágico de la literatura tardía de Alejandría sobre ciencias pseudonaturales que tampoco puede deberse a Juan "el Gramático".

6. Así pues todos los escritos árabes que la tradición árabe atribuye a Juan "el Gramático" son apócrifos. Deben borrarse de las obras históricas junto a la leyenda que menciona las relaciones de los eruditos alejandrinos con los conquistadores árabes de Egipto.

Voy a establecer algunas precisiones en este esquema. El Juan de Alejandría que colabora en la génesis de la recopilación docente llamada Dieciséis libros de Galeno es un médico que vive en la Alejandría de siglo VII y presencia la entrada de los árabes en 641. A la misma persona se deben los resúmenes de aquellos escritos pseudogalénicos. No puede admitirse, en cambio, su autoría de la historia de la medicina griega ni del comentario al primer libro del De antidotis de Galeno aunque estos aún pertenecen menos a la herencia de Juan "el Gramático". Los Dieciséis libros de Galeno y sus comentarios abreviados serían manuales de estudio en la escuela médica de Alejandría. Allí brillan a principios del siglo VII, y al lado de nuestro Juan, otros cristianos como Pablo de Egina y Aarón cuyas obras ejercen hondo influjo en la naciente ciencia árabe ${ }^{10}$. La fundación del Cairo a mediados del siglo VII, concebida como rival de la cristiana Alejandría, supone el inicio de la decadencia de las escuelas alejandrinas de medicina y filosofía y explica sus traslados hacia el año 718. Entonces se pierden muchos recuerdos y se confunden Juan "el Gramático"(filósofo alejandrino del siglo VI a quien se deben importantísimos Comentarios a Aristóteles) con el médico homónimo del siglo VII (coautor de un manual de medicina vigente en la escuela de Alejandría y responsable de unas notas explicativas que se inspiraban en las doctrinas galénicas).

\footnotetext{
${ }^{10}$ Vid. M. MEYERHOF, "Von Alexandrien nach Bagdag. Ein Beitrag zur Geschichte des philosophischen und medizinischen Unterrichts bei den Arabern", Sitzungsberichte der Preussischen Akademie der Wissenschaften. Philologisch-historische Klasse, 23, 1930, pág. 393.
} 